\title{
2D LARGE-EDDY SIMULATION OF WATER-WAVE IMPACT DURING VIOLENT OVERTOPPING EVENTS
}

\author{
Xin $\mathrm{Lv}^{1}$, Qingping Zou ${ }^{1}$, and Dominic Reeve ${ }^{1}$
}

\begin{abstract}
In this work a newly developed numerical model was employed to conduct comprehensive numerical modeling to investigate the waves overtopping at a vertical seawall, and the associated impact pressures with a certain breaking wave condition. The objective is to qualitative and quantitative understanding of individual violent wave overtopping events on seawalls.
\end{abstract}

Keywords: CFD modeling; focus wave; waves overtopping; wave impact

\section{INTRODUCTION}

Wave overtopping happens in a discrete manner when a serials of waves arriving at the sea wall. During this process, disastrous consequences can arise from the effect of one or two extreme waves. The impacts of these waves on the sea wall create much larger velocities and pressures than those associated with the rest ordinary waves. The primary aim of this work is to conduct comprehensive numerical modeling to investigate individual overtopping volumes, surface elevations, impact velocities and pressures associated with different breaking wave conditions. The objective is to compare the numerical results with the measured results by Jayaratne et al. (2008) to provide an improved qualitative and quantitative understanding of individual violent wave overtopping events on seawalls.

\section{EXPERIMENTS}

Fig. 1 shows the experimental set-up used by Jayaratne et al. (2008). Six resistance-type wave gauges were deployed to collect surface elevation data at different locations in front of the structure. The vertical wall is investigated in this study. The wave flow field evolution is captured using a highspeed digital video camera. During the experiments, the water depth at the toe of the structure was kept constant. Tests were repeated to carry out a comparison of wave flow field, impact pressure, overtopping results for the same incident wave conditions.

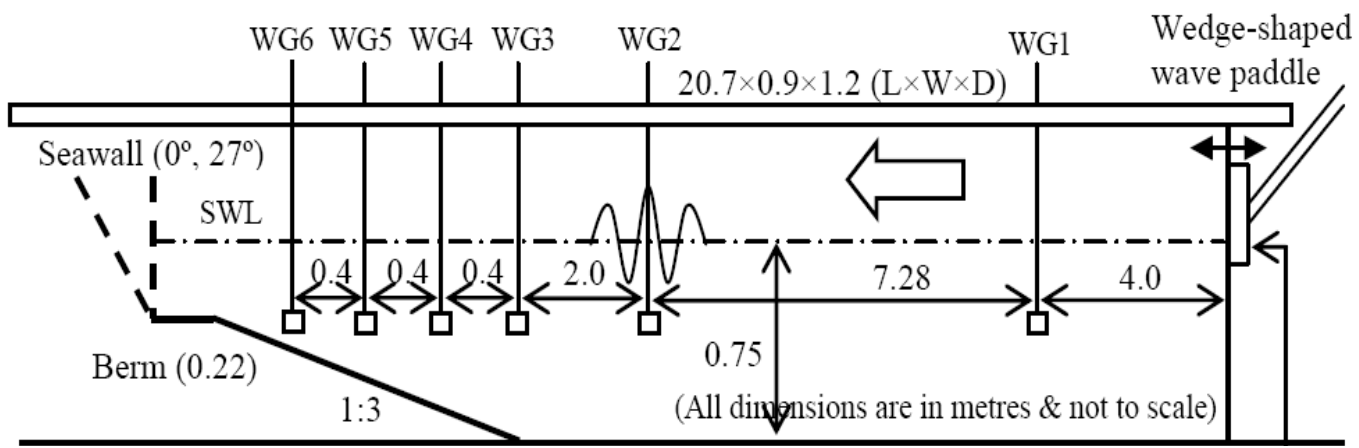

Figure 1. Schematic diagram of wave overtopping experiments (From Jayaratne et al. 2008, Figure 1).

The focused wave group generation method was chosen in order to produce repeatable individual overtopping events. A low-aeration (flip-through) wave, a high-aeration (overturning) wave and a broken wave (turbulent bore) were generated in the experiment based on the classification of Bullock et al. (2007).

\footnotetext{
${ }^{1}$ Centre for Coastal Dynamics and Engineering, School of Marine Science, University of Plymouth, UK
} 


\section{NUMERICAL MODEL}

A novel coupled Level Set (LS) and Volume of Fluid (VoF) method based on Navier-Stokes (NS) equations for interfacial flow simulations on three dimensional unstructured tetrahedral grids is adopted in this study (Lv et al., 2009). At each time step, we evolve both the level set function and the volume fraction. The level set function is evolved by solving the level set advection equation using a high resolution characteristic based finite volume method. The volume fraction advection is performed using a bounded compressive Normalized Variable Diagram (NVD) based scheme (Leonard, 1991). The novelty of the method lies in that we use an analytic method for finding the intercepts on tetrahedral grids, which makes interface reconstruction efficient and conserves volume of fluid exactly. Furthermore, the adaptive combination of high resolution discretization schemes ensures the preservation of the sharpness and shape of the interface while retaining boundedness of the volume fraction field. The method is also coupled to a well validated finite volume based Navier-Stokes incompressible flow solver and has been validated against extensive benchmark test cases ( $\mathrm{Lv}$ et al. 2009, JCP; Lv et al. 2009, IJOPE)

The computational domain is shown in Fig. 2. Non-slip wall boundary condition is applied to the bottom, slope and seawall surface. As where the pressure gauges were installed, the flow properties on a vertical array of three gauge points on the centre-line of the seawall, $0.05 \mathrm{~m}$ apart from each, were monitored. The points were located at $0.10,0.15,0.20 \mathrm{~m}$ elevations above the berm for vertical walls (designated as $\mathrm{P} 1, \mathrm{P} 2$ and $\mathrm{P} 3$ respectively).

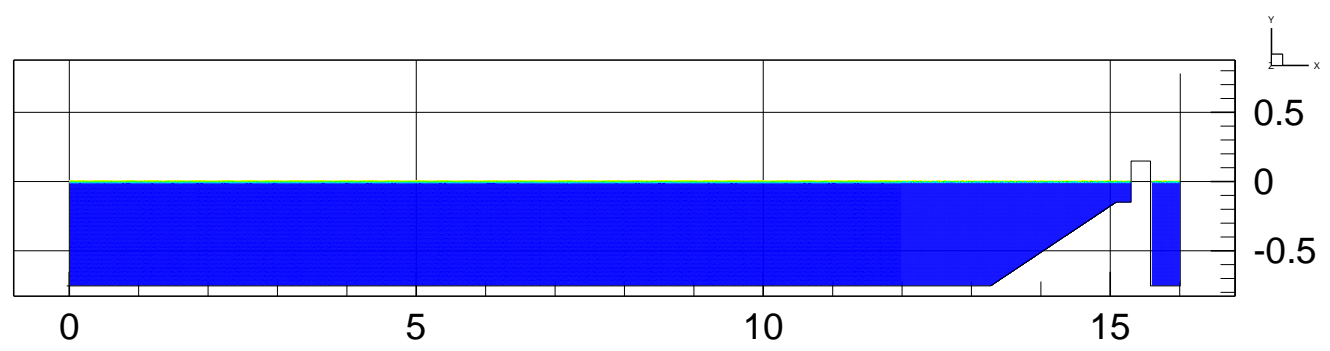

Figure 2. Schematic view of computational domain. Meshes are locally refined near the slope and seawall.

\section{NUMERICAL RESULTS}

The snapshots given in Fig. 3 show time evolutions of a typical wave overtopping process during a wave cycle. The predicted pressure time series at wall monitoring locations (placed at $0.1 \mathrm{~m}, 0.15 \mathrm{~m}$ and $0.2 \mathrm{~m}$ above the berm) for the same wave are shown in Figure 4. The pressure oscillations due to the entrapment of air pocket can be easily found. 


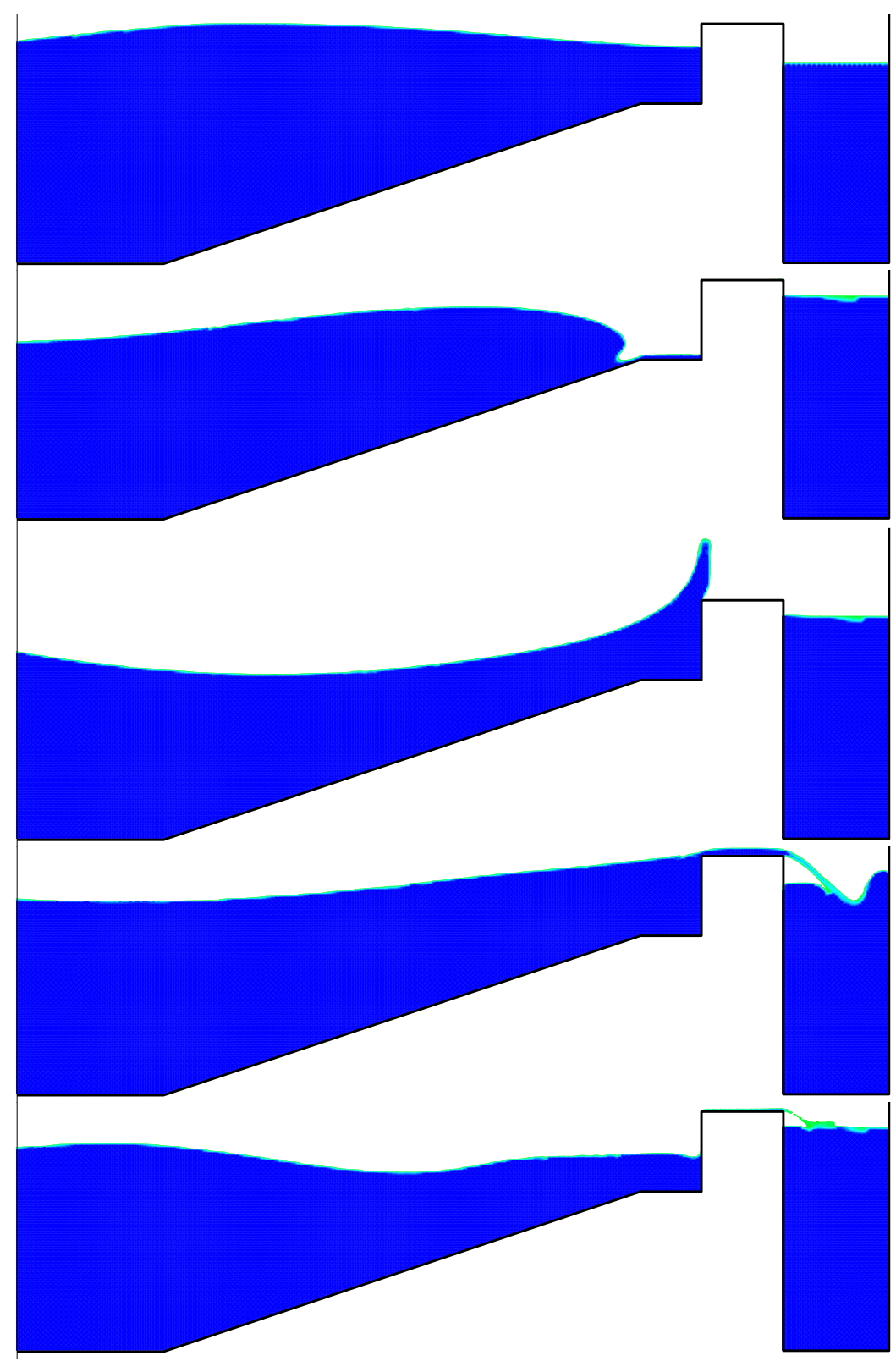

Figure 3. Time evolution of computed wave overtopping. Each snapshot shows a specific time instant during the simulation. The respective times are (from up to down): $12.160 \mathrm{~s}, 12.180 \mathrm{~s}, 12.200 \mathrm{~s}, 12.216 \mathrm{~s}$ and 12.226s. 


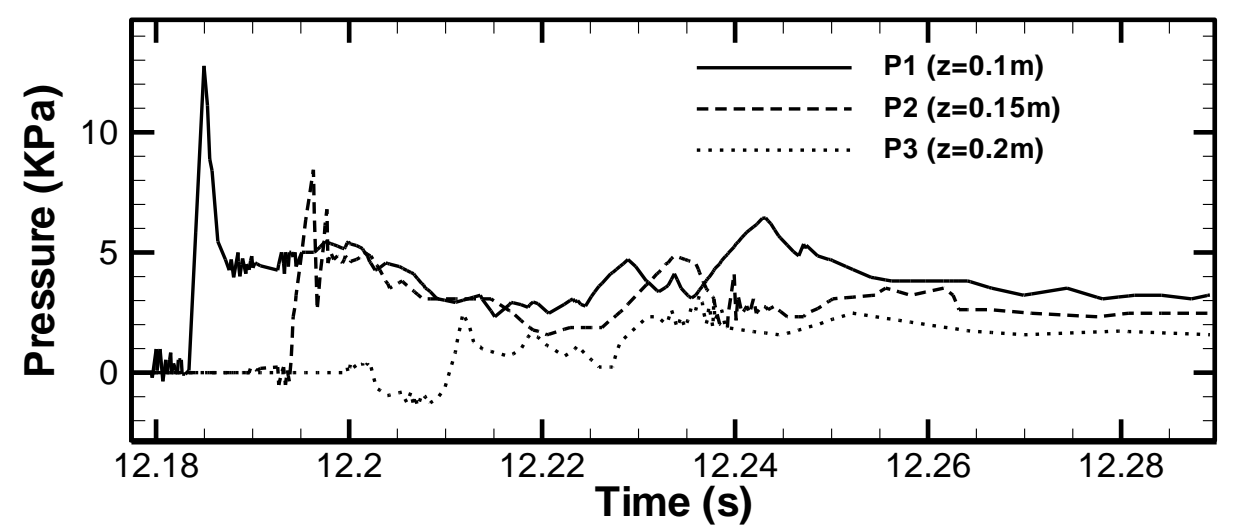

Figure 4. Predicted pressure impact profile time series under the wave shown in Fig. 3 for $0.15 \mathrm{~m}$ freeboard.

As discussed by Baldock and Swan in their early work (1996). The focus of a wave can be adjusted by adding an initial wave shift to each of its Fourier components. This phase shift is determined by the distance between wave maker and the focus point and the wave phase speed (celerity) of that particular Fourier component. The wave phase speed is a function of frequency and water depth. A close look of Fig. 3 shows that the wave focused at a point before seawall. Following this method, another test was performed by adjust the wave focus so that the big entrapped air bubble due to the overturning of the breaking wave can be easily seen, as shown in Fig. 5. The corresponding pressure impacts are shown in Fig. 6 next.

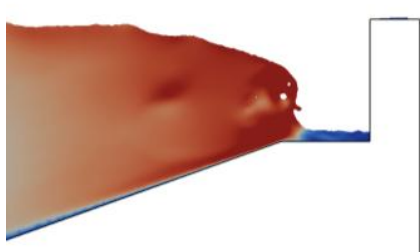

(1).
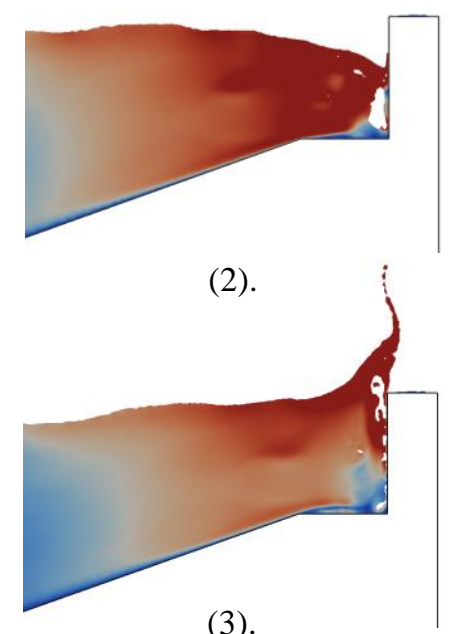

(3).

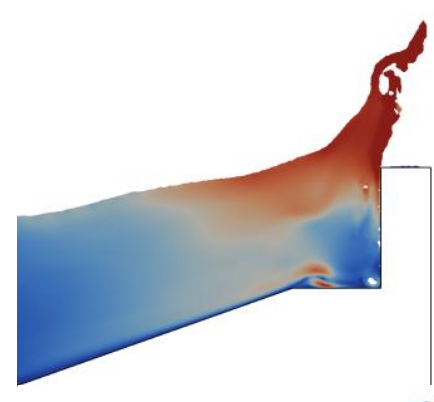

(4).
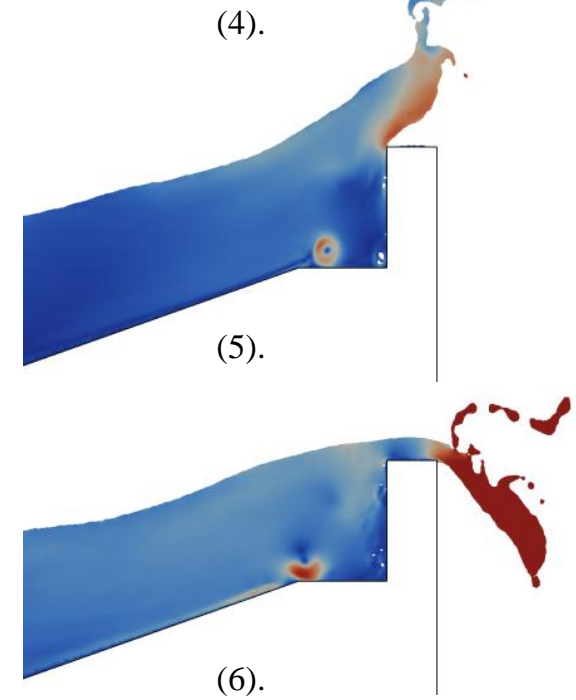

Figure 5. Time evolution of computed wave overtopping. Each snapshot shows a specific time instant during the simulation. The respective times are (from up to down, and left to right): 11.130s, 11.150s, $11.170 \mathrm{~s}, 11.187 \mathrm{~s}$ and $11.202 \mathrm{~s}$. The water is colored by absolute velocity magnitude. 


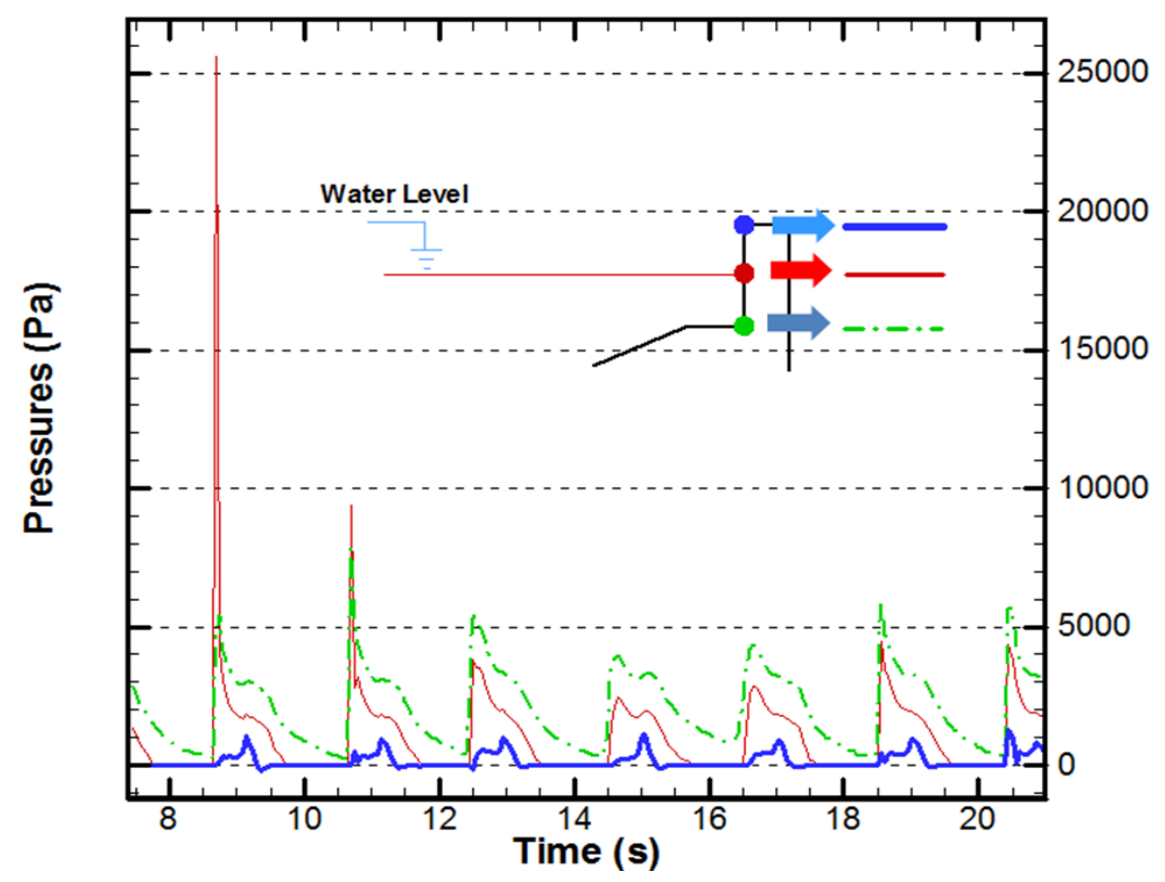

Figure 6. Predicted pressure impact profile time series under the wave shown in Fig. 5 for $0.10 \mathrm{~m}$ freeboard.

\section{SUMMARY AND DISCUSSION}

As shown in previous section, our model is able to produce the impulse and oscillation of wave impact similar to those observed in Bullock et al. (2007) for different breaking wave types on the seawall. Thus the numerical model employed in this work provides us a good opportunity in further understanding of the overtopping process. Overtopping from individual violent impact events has been investigated numerically using two different types of waves. As the future work, the measured surface elevation time histories and pressure impact will be reproduced using the current numerical model. The relationship between wave types and the focus position as well as amplitude will be further examined. 3D effects on wave impact will be investigated in full detail.

\section{ACKNOWLEDGMENTS}

This research was supported by the Flood Risk from Extreme Events (FREE) Programme of the UK Natural Environment Research Council (NERC) (NE/E0002129/1), coordinated by Professor Chris Collier. The numerical calculations have been carried out on the HPC facility at the University of Plymouth.

\section{REFERENCES}

Baldock, T.E., and C. Swan. 1996. Extreme waves in shallow and intermediate water depths, Coastal Engineering, 27, p. 21-46.

Bullock, G.N., C. Obhrai, D.H. Peregrine, and H. Bredmose. 2007. Violent breaking wave impacts. Part 1: Results from large-scale regular wave tests on vertical and sloping walls, Coastal Engineering, 54, p. 602-617.

Leonard, B.P. 1991. The ULTIMATE conservative difference scheme applied to unsteady onedimensional advection, Computational Method in Applied Mechanical and Engineering, Vol. 88, p. 17-74.

Lv, X., Q.P. Zou, Y. Zhao, and D.E. Reeve. 2009. A novel coupled level set and volume of fluid method for sharp interface capturing on 3D tetrahedral grids, Journal of Computational Physics, Volume 229, Issue 7, p. 2573-2604, doi:10.1016/j.jcp.2009.12.005. 
Lv X., Q.P. Zou and D.E. Reeve. 2009. A hybrid level set and volume of fluid method for 3D simulation of wave breaking and overtopping, International Journal of Offshore and Polar Engineering, Vol. 19, No. 4, p. 308-316.

Jayaratne, R., A. Hunt-Raby, G. Bullock, and H. Bredmose. 2008. Individual violent overtopping events: new insights, Proceedings of 31st International Conference on Coastal Engineering (31st ICCE), ASCE, Hamburg (in Press). 